Contents List available at VOLKSON PRESS
Education, Culture and Social Development (ECSD)
DOI : http://doi.org/10.26480/icecsd.01.2018.41.43
Journal Homepage: : https://topicsonsocialdevelop.com/

\title{
THE RESEARCH OF COMPUTER SPECIALTY COURSE SYSTEM BASED ON ABILITY STANDARD
}

\author{
Teng Haikun*, Liu Xinsheng, Li Lunbin \\ Computer and Information Engineering College, Heihe University Academic Road No. 1, Heihe City, China. \\ *Corresponding Author email: thk 1983@163.com
}

This is an open access article distributed under the Creative Commons Attribution License, which permits unrestricted use, distribution, and reproduction in any medium, provided the original work is properly cited

\section{ARTICLE DETAILS}

\section{Article History:}

Received 12 November 2017 Accepted 12 December 2017 Available online 1 January 2018

\section{ABSTRACT}

At present, the awareness of the cultivation to talents is gradually increasing, and the most obvious embodiment lies on the further requirements of the social and employing units on the quality of college students, which also makes the course system construction of the colleges and universities face some challenges. This paper analyzes the specific connotation of CBE curriculum system and aiming at one of the most popular majors in our country, the course system of computer speciality is combined with CBE thinking, and some problems are analyzed, and the concrete method of constructing the computer speciality curriculum system based on CBE is put forward.

\section{KEYWORDS}

Undergraduate institutions, CBE, Computer science, Curriculum system.

\section{INTRODUCTION}

As a core part of higher education institutions, whether the undergraduate colleges and universities can combine the specialty characteristics with the subject characteristics, the key factors of training quality of professional curriculum system based on CBE are established [1]. With the progress of society and the development of information technology, computer professionals have become more and more important targets of enterprises and social units, which has made more and more students take computer majors as their major volunteers. It's a good thing that students ' love of computers has reached an all-time high. However, this situation also challenges the training task of computer professionals [2]. Therefore, it is one of the most important tasks for computer professional educators in undergraduate colleges to explore the curriculum system of computer specialty based on CBE.

\section{THE CONNOTATION AND SIGNIFICANCE OF CBE COMPUTER SPECIALTY CURRICULUM SYSTEM}

The CBE concept comes from the CBE vocational Education thought, its core lies in the training student's ability, through carries on the Omnidirectional analysis to the student's study subject content and carries on the comprehensive ponder to the student use knowledge application request, thus enhances the student in the related profession competitive power, So that students can in the real sense of a good professional competitiveness [3]. In fact, CBE's thought is the continuation of quality education in the compulsory education period, whose essence is to prevent excessive skill training from affecting the students ' comprehensive quality, so that the students lack the core competence in the fierce employment competition, which is contrary to the expected target of higher education personnel training. At the same time, the use of CBE to carry out the design of professional curriculum system can help students to master good learning methods and ways of thinking, and cultivate their own innovative thinking, to their own career development has a great degree of help.

The concept of curriculum system has been mentioned many times in education practice in recent years, and it is thought that the curriculum system includes many aspects, such as curriculum goal setting, course Content Selection, curriculum design, teaching work implementation and curriculum feedback evaluation, through the comprehensive analysis of the course. and from different angles to the course of each part of the process of thinking and detail assignment to achieve the best results of the course: The curriculum goal setting mainly aims at the students ' performance in skills improvement and ability promotion, which can be obtained through the course, and is the expected reflection to the educational achievement, and can also guide the overall direction of the course [4]. The course content is to the curriculum goal through unifies the specialized knowledge, the general knowledge carries on the concrete practice the content, lets the curriculum to the student study expectation with the detail each class carries on the performance respectively; The curriculum involves the types of courses, the sequencing of teaching and the proportion of each part, etc.

Be able to coordinate the course content in general, in order to better achieve the objectives of the curriculum, the implementation of the teaching work is the specific time of the curriculum, so that the theoretical thinking of the curriculum and link design can be linked to students ' learning activities, is the curriculum system can apply the teaching effect, and the teaching objectives have a direct reflection of the key link; The evaluation feedback of the course is aimed at the end of the course, by thinking and evaluating the four parts mentioned above, the teachers and students judge the value of the course and make adjustments to each part of the course. In addition, a good curriculum assessment can update the curriculum objectives, To ensure the practical significance of the curriculum, the curriculum development or general direction of development has a very important guiding role. These five parts are the only basis for the analysis of the course system of computer speciality in the following sections.

At present, the professional curriculum system based on CBE has been practiced in different degrees at home and abroad, while some advanced curriculum models in Western countries, such as the German dual system model and the CBE model in Canada, have more mature practice. Germany's dual system emphasizes the combination of school and 
enterprise, and the training goal of talents needs to be combined with the requirements of enterprises to a large extent; the CBE model in Canada is similar to that of the students ' ability training objectives, and to different occupations will be from knowledge, attitude, Skills and feedback four aspects of in-depth and comprehensive training, these models can provide a great degree of reference for the design of computer professional curriculum system in China. Undergraduate colleges and universities can combine the characteristics of the curriculum itself on the basis of appropriate to enable students to contact the enterprise-related level of personnel training programs, personnel capacity requirements, so that students improve their knowledge of practical application ability, and then realize the overall improvement of computer capabilities.

\section{PROBLEMS EXISTING IN THE COURSE SYSTEM OF COMPUTER SPECIALITY IN UNIVERSITIES}

\subsection{The course setting of computer specialty is unreasonable}

There are some problems in the course setting of computer speciality in Chinese universities. The speed of the traditional computer-related content is not fast, and a lot of computer software and language use there is a large degree of connectivity, so in the course of college courses are not the development of the vision to look at the problem, many schools have not followed the trend of the development of the Times, the curriculum set to update. At present, the specialty of computer is to develop quickly and professionally, but for a certain kind of content (such as ASP and HTML5 language in Web programming, MySQL and Oracle in database technology, data acquisition, storage and management in large data processing technology), Although there are similarities between the basic concepts, human-computer interaction, logical thinking, algorithm implementation and other aspects of the content may be a great difference, so the university's professional setting of computers need to fully consider the objective needs, rather than just the years or even decades before the model.

For example, many schools will still use $\mathrm{C}$ as the basis for training students in programming language, and there is no shortage of schools to set up Visual Basic programming language courses; However, students themselves in the early high school can largely complete the basic part of $\mathrm{C}$ language learning, At the same time, objective $\mathrm{C}$ language in the relevant basic algorithm training relative to Java, $\mathrm{C}$ \# does not have the advantage of learning on the threshold, such as Python and other Up-and-comer can replace the traditional location of $\mathrm{C}$ language, which makes the school of related programming courses in the lack of forward-looking, thus affecting the cultivation of students ability. If the curriculum of colleges and universities can not cater to the trend of computer technology development, it is very difficult for students to achieve their own practical improvement.

\subsection{There is no fundamental change in teaching methods}

In the teaching methods, many teachers do not recognize the "studentcentered" modern educational ideas of the specific connotation, still in the classroom education through a large number of knowledge teachings or read the textbook to guide students to understand the course content, grasp the relevant knowledge. This method is difficult to improve the classroom efficiency of students, and it is difficult to let students through the normal classroom learning links to the study of the content of in-depth thinking, not to mention the ability of students to develop. In addition, although the majority of colleges and universities have adopted the teaching means of information, but the teacher just followed the previous teaching methods, the teaching content from textbooks and blackboard to the PPT or micro-curriculum resources, and the teaching content is not timely update, which will affect the individual development of students, and hinder the development of students ' comprehensive ability.

\subsection{Teaching evaluation and assessment cannot reflect the actual} ability of students

Teaching evaluation and assessment work can measure and judge the realization of the expected goals of the course, and accurately reflect the students ' ability, but it needs to be established under the prerequisite of the comprehensive assessment method and the objective condition of the evaluation mechanism. At present, many undergraduate schools still emphasize the assessment of students ' basic theory knowledge and pass the score assessment as the main evaluation factor of the students knowledge Mastery, which plays down the part of the students ' ability to solve the practical project with theoretical knowledge. This will be to a certain extent let students produce wrong learning mentality, can not form a better use of theoretical knowledge to solve practical problems.

\section{THE ESTABLISHMENT BASED ON CBE COMPUTER SPECIALIZED CURRICULUM SYSTEM CONCRETE METHOD}

\subsection{Clear the target orientation of talent training}

The undergraduate college should fully understand the stage goal of the training of computer talents. First, the teachers of computer science should fully realize the modern education thought of guaranteeing the students ' subject status in the modern education, make the students as the main body in the course of designing the curriculum system, and try to arouse the students ' subjective initiative in the teaching practice, so that the students can consciously participate in the classroom teaching process. To provide protection for the improvement of teaching achievement; Secondly, the relevant educators should keep in touch with the relevant enterprise personnel, and with the help of scientific research and the forefront of research in the computer industry (such as in-depth learning, data mining, etc.) to grasp the current industry to the specific needs of talent direction, And to make a bold estimate of the demand for talent in the next phase, it is necessary to adjust and arrange the curriculum, so that the training of talents can follow the trend of the times and even advance to the times, so that the goal of talent training can be defined, so that the students will be able to improve their abilities through the course learning of undergraduate courses.

\subsection{Reform the course content and teaching methods}

The computer professional teaching staff should also pay attention to the existing curriculum content and curriculum teaching methods to update, so that the curriculum system with the times, with the necessary time elements. First of all, teachers should have a good industry vision, for the current stage of the rapid rise of the relevant technology, programming language, professional software, such as all-round inspection, will be able to carry out teaching practice part of the teaching content, such as the current in various fields play a greater role in the Python language, And the new theory of image recognition technology; Secondly, teachers should give full play to students ' main position in the course of teaching, encourage students to expand their study and cooperate with each other, and set up a series of classroom exploration and curriculum design, so that students can carry out practical project practice and improve their ability to apply theoretical knowledge. So as to improve students ' professional quality comprehensively.

4.3 The establishment of a diversified curriculum evaluation mechanism

The curriculum evaluation of computer majors should be of multiple, comprehensive and objective characteristics. On the one hand, the traditional form of performance assessment can be a certain degree of reservation; Teachers can adjust the students ' theoretical knowledge in written or on the basis of the proportion of the study, to ensure that the basic knowledge of students to meet the expected requirements of the curriculum; On the other hand, teachers should do little homework, The design of the project and the development of the students ' innovative projects will make the students realize the essential connotation of the practice of computer professional knowledge so as to help them improve their own ability to use the computer theory.

\section{CONCLUSION}

The establishment of a computer professional curriculum system based on $\mathrm{CBE}$ is of great practical significance for undergraduate education, and it can provide the guarantee for the practice of talent Training program and the improvement of students ' professional ability. Therefore, the teaching staff of computer majors should fully understand the connotation of CBE curriculum system, make clear the target of personnel training, renew the 
teaching content and teaching means, and try to establish a pluralistic teaching evaluation mechanism, and then play an active role in establishing the new curriculum system of computer specialty.

\section{ACKNOWLEDGEMENT}

This paper is supported by 2017 Advanced Education Teaching Reform Research of The General Research Project--Computer Science and Technology Specialized Course Setting Study Based on the Ability (ID: SJGY0209).

\section{REFERENCES}

[1] Wenlian, W. 2017. Research on the training of applied undergraduate talents in the perspective of CBE Education [J]. Jiangsu Higher Education, $2,44-48$.

[2] Wei, S., Jian, G. 2017. The construction of curriculum system based on professional ability--taking computer network technology specialty as an example [J]. Journal of Liaoning Higher Vocational College, 19 (2), 59-61.

[3] Ling, L. 2015. Research on the development of curriculum system based on CBE and differentiation--taking the computer specialty of Huaibei vocational and technical College as an example [J]. Journal of Qinzhou College, 30 (5), 72-76.

[4] Keding, Z. 2015. On the human-oriented regression of the thinking ability of computer course computing in university [J]. University teaching in China, (7), 51-55+84. 